\title{
Jornalismo de Dados como diferencial: o caso do $\mathrm{NexO}^{1}$
}

\section{Mariane Pires Ventura²}

\section{Resumo}

O Jornalismo de Dados é cada vez mais utilizado pelos veículos como um recurso para se diferenciar no mercado assim como atrair a audiência. Com base nos estudos de Vasconcellos; Mancini e Bittencourt (2015), observa-se que existem diferentes níveis de utilização dos dados, podendo ele ser classificado de Jornalismo de Dados ou Jornalismo com Dados. Este artigo aplica a matriz dos autores como metodologia de análise para nove matérias publicadas pelo Nexo. O referido veículo tem sido visto e premiado como um case de sucesso no jornalismo inovador e ao final dessa pesquisa é possível verificar que, de certo modo, a aposta na utilização dos dados pode estar contribuindo para isso.

Palavras-chave: Jornalismo de Dados. Base de dados. Nexo.

\section{Abstract}

Data Driven Journalism is increasingly being used by media as a way of differentiating themselves in the marketplace as well as attracting the audience. Based on the studies of Vasconcellos; Mancini and Bittencourt (2015), it is observed that there are different levels of use of the data, which can be classified as Data Journalism or Journalism with Data. This article applies the authors' studies as a methodology to analysis for nine articles published by Nexo. This media has been seen and awarded as a success case of innovative journalism, and at the end of this research, it is possible to verify that, in a way, the bet on the use of the data may be contributing to this.

Keywords: Data Journalism. Database. Nexo.

\section{Introdução}

Do século $\mathrm{XV}$ ao $\mathrm{XXI}$, os meios de comunicação e a forma como as pessoas trocam informação e interagem passaram por várias mudanças. A maioria delas teve a internet como precursora. Castells (2003) compara a tecnologia da informação como

1 Este artigo conta com apoio financeiro da Coordenação de Aperfeiçoamento de Pessoal de Nível Superior (CAPES).

2 Doutoranda em Jornalismo pelo Programa de Pós-graduação em Jornalismo da Universidade Federal de Santa Catarina. Mestre e graduada em Jornalismo pela mesma instituição. E-mail: mariventura2@gmail.com.

Revista Pauta Geral-Estudos em Jornalismo, Ponta Grossa v.5, n.2, p. 240-254,

Jul/Dez 2018. 
sendo equivalente à eletricidade na Era Industrial, a internet poderia ser nivelada a uma rede ou motor elétricos devido a sua capacidade de disseminar a informação e servir como alicerce tecnológico para a Era da Informação (CASTELLS, 2003). Da maneira como o motor elétrico permitiu o desenvolvimento de uma gama de maquinários, a internet possibilitou a dispersão de dados na rede com um alcance imensurável, e partir dos anos 1990, a Web passou a ser empregada para atender finalidades jornalísticas de modo mais expressivo (MIELNICZUK, 2001). O grande volume de dados disponíveis na rede também possibilitou novas formas de apuração e divulgação de conteúdo noticioso, entre eles o chamado Jornalismo Guiado por Dados (JGD) ou Jornalismo de Dados (JD), que neste trabalho serão adotados como sinônimos.

Anderson, Bell e Shirky (2013) no relatório Jornalismo Pós-industrial: adaptações aos novos tempos frisam a importância da utilização dos dados como uma estratégia de inovação para a crise no modelo de negócio do jornalismo, que há anos vem sofrendo com queda das receitas advindas dos anunciantes. Na visão de Gray, Bounegru e Chambers (2014, online), hoje "o jornalismo guiado por dados 'está na moda"”.

\begin{abstract}
Além da popularização das ferramentas e do apelo comercial de visualizações e outros produtos relacionados ao JGD, foi importante para isso a adoção de políticas de acesso à informação e transparência por governos de todo o mundo. Conhecidos como políticas de "dados abertos" (open data) ou "transparência pública" (open government), estes mecanismos inundaram a Internet com bases de dados antes muito difíceis de se obter. Os jornalistas, portanto, têm hoje o material e as ferramentas para o JGD ao alcance das mãos (GRAY; BOUNEGRU; CHAMBERS, 2014, online).
\end{abstract}

Observam-se dois caminhos propiciados pela disponibilização dos dados na rede: a possibilidade da automação da produção de conteúdos e a sua utilização como fonte para apuração de reportagens, muitas vezes de interesse público, tendo em vista a política da "transparência pública". O segundo aspecto será mais bem desenvolvido adiante.

Para Gray, Bounegru e Chambers (2014, online) o JGD também se difere do restante do jornalismo devido as "possibilidades que se abrem quando se combina o tradicional 'faro jornalístico' e a habilidade de contar uma história envolvente com a escala e o alcance absolutos da informação digital agora disponível". E as inovações acontecem em qualquer parte do processo de produção de conteúdo: os dados servem de fonte para 
a pauta tanto quanto podem ser o núcleo da matéria. Além disso, existem várias ferramentas disponíveis para ajudar na coleta, mineração e combinação dos dados, que facilitam o trabalho do profissional e reduzem as chances de erros. O uso dos dados também permite a formulação de reportagens mais complexas e a criação de infográficos que atraem e envolvem o leitor. Muitos jornais já se atentaram para esse fato e passaram a investir na formação de uma equipe de jornalismo dados.

No livro organizado pelo Knight Center, Jornalismo Inovador na América Latina, são mostrados vários exemplos de veículos que encontraram no JGD uma forma de se manter no mercado e atrair o público, como é o caso do La Nacion, Ojo Público, e o Nexo. Esse último foi escolhido para ser o nosso objeto de estudo por ser um exemplo de veículo jornalístico brasileiro que aposta no JGD como um recurso de inovação.

Vistas as tendências e possibilidades proporcionadas pejo JGD, objetiva-se verificar as diferentes formas de produção de matérias baseadas em dados. Para tanto, emprega-se como metodologia de análise a classificação do Jornalismo de Dados desenvolvida por Vasconcellos; Mancini e Bittencourt (2015). O procedimento metodológico se constituiu em uma análise qualitativa de nove matérias publicadas pelo Nexo, tal corpus é composto pela união das três reportagens mais lidas nas categorias Interativo, Especial e Gráficos. Ao final das análises, verifica-se que o Nexo utiliza diferentes modelos de aplicação dos dados e um maior número de matérias oferece gráficos interativos, mas deixa a interpretação dos dados ao cargo do leitor.

Como forma de estruturar este artigo e fazer uma problematização teórica de aspectos que envolvem o jornalismo de dados antes da análise empírica, o conteúdo foi dividido em três a partes. A primeira faz um apanhado histórico da utilização dos dados pelo jornalismo e as origens do JGD; a segunda trata das especificidades do Nexo; na terceira é apresentado o recurso metodológico utilizado e a análise do corpus.

\section{Do Jornalismo de Precisão ao Jornalismo Guiado por Dados}

Segundo os editores do Manual de Jornalismo de Dados, Gray, Bounegru e Chambers (2014), a primeira referência a Data Journalism (Jornalismo de Dados) foi feita em 2006, pelo programador Adrian Holovaty (2006) no seu artigo A fundamental way newspapers sites need to change, no qual ele defende a adoção de técnicas de gerenciamento de banco de dados como parte da rotina das redações, o que poderia facilitar o reaproveitamento das informações coletadas diariamente na apuração das Revista Pauta Geral-Estudos em Jornalismo, Ponta Grossa v.5, n.2, p. 240-254, Jul/Dez 2018. 
reportagens. "Para além dos aspectos técnicos e narrativos, entretanto, O JGD busca essencialmente introduzir a racionalidade científica nas rotinas de produção jornalística" (TRÄSEL, 2014b, p. 293).

Para Mancini e Vasconcellos (2016), apesar de o jornalismo dados ser considerado algo relativamente recente, o termo faz parte de uma tradição que teve início na década de 1960 pelo jornalista Philip Meyer. Segundo os autores, ele foi um dos primeiros pesquisadores a utilizar o conceito "Jornalismo de Precisão", que ocorria por meio da utilização do computador associado às metodologias das ciências sociais para produzir reportagens com maior índice de exatidão.

Utilizando essa combinação, em 1967, Meyer escreveu a reportagem The People Beyond 12th Street, a qual foi vencedora do Prêmio Pulitzer no mesmo ano. A matéria foi escrita quando a cidade de Detroit passava por um período de conflito social após uma invasão da polícia a um bar clandestino no local, fato que foi o estopim para que os moradores da região promovessem manifestações durante cinco dias. Resultando na destruição de várias ruas da cidade, 43 mortos e 7 mil detidos. Não havia, até aquele momento, uma razão clara para justificar os ataques e a cobertura da mídia sugeria a possibilidade de que os manifestantes pertencessem a camadas econômicas mais baixas e com menor grau de escolaridade ou que imigrantes, negros na maioria, estariam causando os motins como forma de protesto à sua falta de inserção na cultura local (RODRIGUES, 2015; ROSEGRANT, 2011, online).

Nessa época, Philip Meyer havia recentemente terminado seus estudos no curso de estudando ciências sociais em Harvard e trabalhava como correspondente nacional para a revista Knight Newspapers, pertencente ao grupo Free Press. Meyer foi para Detreoit ajudar a equipe da Free Press e sugeriu a aplicação de um questionário que contemplasse uma amostra representativa dos moradores dos bairros afetados para investigar a identidade e o comportamento daquelas pessoas. Nathan Caplan, psicólogo do Instituto de Pesquisa Social da Universidade de Michigan, também estava interessado em descobrir os motivos da rebelião e se uniu a Meyer para realizar o estudo. Um mês após os ataques, em 20 de agosto de 1967, o Detroit Free Press e outros jornais do grupo publicaram o relatório com a três principais conclusões: a) não havia relação entre a classe econômica e participação nos motins; b) os moradores com graduação eram tão propensos a participar dos ataques quanto aqueles que não terminaram o ensino médio; c) os imigrantes do Sul não tiveram participação significativa nos ataques, enquanto que Revista Pauta Geral-Estudos em Jornalismo, Ponta Grossa v.5, n.2, p. 240-254, Jul/Dez 2018. 
os norte-americanos eram três vezes mais propensos a se rebelar. Além disso, constatouse que os principais motivos para as rebeliões foram a truculência da polícia, as más condições de moradia e a falta de empregos. O relatório também mostrou que os manifestantes eram um subgrupo específico e não refletiam a atitude da maioria da comunidade negra. O que contribuiu para a atenuação das rivalidades em Detroit (TRÄSEL, 2014; ROSEGRANT, 2011).

Seis anos depois, em 1973, com base nessa e outras experiências, Meyer publicou o livro Precision Journalism relatando como os métodos das ciências sociais e da computação poderiam ser apropriadas pelos jornalistas como forma de se aproximar o máximo possível da verdade. Meyer argumentava que combinando técnicas de coleta da sociologia e a rapidez de cálculo dos computadores, que nesse período estavam se tornando mais acessíveis, seria possível uma apuração mais objetiva (TRÄSEL, 2014).

Ao passar do tempo, a utilização de dados numéricos se tornou mais recorrente nas reportagens e a informatização das redações também contribuiu para o crescimento do interesse pelo jornalismo de precisão, que posteriormente veio a ser denominado como Reportagem Assistida por Computador (RAC) (TRÄSEL, 2014; RODRIGUES, 2015).

Para Träsel (2014b) por meio dos conceitos e do desenvolvimento da RAC e do Jornalismo de Precisão foi possível chegar às práticas denominadas hoje como Jornalismo Guiado por Dados (JGD) e Jornalismo em Bases de Dados (JBD). Técnicas que, a partir dos anos 2000, se propagaram nas redações da América do Norte e Europa, além de se tornarem a principal estratégia da imprensa para a recuperação da audiência que há muito já vinha em queda (GRAY; BOUNEGRU; CHAMBERS, 2014; TRÄSEL, 2014b).

Dessa forma, a incorporação de informações numéricas em conteúdo jornalístico se tornou mais recorrente e passou a ser utilizada como forma de legitimação do discurso. Vista a premissa de que os números são neutros e objetivos. Porém, a narrativa construída por meio dos dados e aliada à infografia também passa pelo processo de seleção e interpretação do jornalista, que mesmo com o auxílio dos computadores e ferramentas de pesquisa e análise ainda é passível de falhas. Como alerta Meyer (2002, p.19): "os números são como fogo. Eles podem ser usados para o bem ou para o mal. 
Quando mensurados, eles podem criar ilusões de certeza e importância que nos tornam irracionais" ${ }^{3 n}$.

Observando o exemplo da experiência de Meyer, relatada anteriormente, e a maneira pela qual as redações se apropriaram do JGD, como estratégia para manter a credibilidade e trazer para leitor novas leituras das informações disponíveis na rede, trazemos a seguir o caso do jornal online brasileiro Nexo para ilustrar o cenário atual do JGD.

\section{Objeto de estudo: Nexo Jornal}

O site de notícias Nexo é um jornal digital fundado em 2015 por uma cientista social, Paula Miraglia, uma engenheira, Renata Rizzi, e um jornalista, Conrado Corsalette. Desde a sua fundação, o Nexo aposta numa equipe multidisciplinar e tem como proposta dar mais espaço para um jornalismo de contexto, que explique as informações dos noticiários por meio de reportagens multimídia, interativas e de dados (ESTARQUE, 2017). Conforme a sua própria descrição no site, o Nexo tem como compromisso oferecer para os leitores "informações contextualizadas, com uma abordagem original. Para o Nexo, apresentar temas relevantes de forma clara, plural e independente é essencial para qualificar o debate público" (NEXO, 2015, online).

Para Mariana Menezes, editora executiva, em entrevista para o Knight Center, o Nexo tem "[...] outro olhar para o que é notícia, justamente porque não há só jornalistas. $\mathrm{O}$ nosso cientista de dados, por exemplo, que faz a coleta e pesquisa, é biólogo e programador. Temos essa preocupação de ter pessoas de várias áreas, pensando de formas diferentes" (ESTARQUE, 2017, p. 65). Menezes destaca como exemplos o especial interativo ${ }^{4}$ para que os leitores testassem seu conhecimento sobre a localidade onde moram, fornecendo informações como o número de domicílios que têm acesso a esgoto, luz ou água encanada; o especial ${ }^{5}$ sobre ruas contanto a origem dos seus nomes,

3 Citação original: "Numbers are like fire. They can be used for good or ill. When measured, they can create illusions of certitude and importance that render us irrational" (tradução nossa).

4 Disponível em: <https://www.nexojornal.com.br/interativo/2016/09/27/Voc\%C3\%AAconhece-bem-a-realidade-da-sua-cidade-Fa\%C3\%A7a-o-teste>. Acesso em 25 mai. 2018.

5 Disponível em:< https://www.nexojornal.com.br/especial/2016/02/15/Nomes-de-ruasdizem-mais-sobre-o-Brasil-do-que-voc\%C3\%AA-pensa>. Acesso em 25 mai. 2018.

Revista Pauta Geral-Estudos em Jornalismo, Ponta Grossa v.5, n.2, p. 240-254,

Jul/Dez 2018. 
utilizando o banco de dados dos Correios; o jogo ${ }^{6}$ de palavras cruzadas acerca do processo de impeachment da presidenta Dilma Rousseff. Todos esses especiais foram produzidos utilizando o JGD e dando nova leitura para "informações velhas" (ESTARQUE, 2017, p. 66).

Em 2017, o Nexo foi o primeiro veículo brasileiro a ganhar a maior premiação do Online Journalism Awards na categoria "Excelência geral em jornalismo on-line pequenas redações". O evento é considerado o principal prêmio de jornalismo digital no mundo e tinha entre seus finalistas veículos como The New York Times, The Guardian, The Washington Post, competindo em diferentes grupos. No ano anterior, 2016, o jornal digital também recebeu o prêmio $\tilde{N} H$ de melhor publicação digital do ano. Essa premiação é organizada pela filial espanhola da Society for News Design e visa a valorização do design nos meios de comunicação (PIMENTEL, 2017).

A julgar pelos prêmios, parece que o formato do Nexo vem dando certo. Com sede em São Paulo, o jornal conta com trinta colaboradores de diferentes áreas como jornalismo, tecnologias, negócios, arte. Além da equipe enxuta, o Nexo também se difere dos outros veículos por não publicar anúncios no site e cobrar um valor mensal de R\$ 12,00 por assinatura para que usuário tenha acesso ilimitado a todo conteúdo. Os nãoassinantes têm acesso a cinco publicações e à seção de vídeos (NEXO, 2015).

\section{Jornalismo de Dados ou Jornalismo com Dados: breve análise do Nexo}

O Nexo ainda se destaca por possui uma seção destinada a gráficos ${ }^{7}$, reportagens especiais $^{8}$ e interativas ${ }^{9}$, nas quais podem ser encontradas diversas matérias baseadas em dados. Para este artigo, selecionou-se ${ }^{10}$ como corpus as três notícias mais lidas nas categorias citadas (Quadro 1) como forma de verificar se as reportagens se classificariam como Jornalismo de Dados ou Jornalismo com Dados, seguindo a taxonomia elaborada por Mancini e Vasconcellos (2016).

6 Disponível em:<https://www.nexojornal.com.br/interativo/2016/05/09/Palavras-cruzadasimpeachment-e-a-Lava-Jato-em-jogo>. Acesso em 25 mai. 2018.

7 Disponível em:<https://www.nexojornal.com.br/grafico/>. Acesso em 25 mai. 2018.

8 Disponível em:< https://www.nexojornal.com.br/especial/>. Acesso em 25 mai. 2018.

9 Disponível em:<https://www.nexojornal.com.br/interativo/>. Acesso em 25 mai. 2018.

10 Seleção feita de acordo com o ranking de notícias mais lidas no dia 05 de fevereiro de 2018.

Revista Pauta Geral-Estudos em Jornalismo, Ponta Grossa v.5, n.2, p. 240-254,

Jul/Dez 2018. 
ESTUDOS EM JORNALISMO

10.5212/RevistaPautaGeral.v.5.i2.0014

Quadro 1: Matérias do site Nexo selecionadas para análise

\begin{tabular}{|c|c|c|}
\hline Especial & Gráfico & Interativo \\
\hline $\begin{array}{l}\text { A - Os versos e traços da } \\
\text { literatura de cordel } \\
\text { Link para matéria } \\
\text { Publicado em: } 03 \text { mai. } 2017\end{array}$ & $\begin{array}{l}\text { D - A distribuição de pessoas } \\
\text { com doutorado pelo Brasil } \\
\text { Link para matéria } \\
\text { Publicado em: } 23 \text { out. } 2017\end{array}$ & $\begin{array}{l}\text { G - O seu salário diante da } \\
\text { realidade brasileira } \\
\text { Link para matéria } \\
\text { Publicado em: } 11 \text { jan. } 2016\end{array}$ \\
\hline $\begin{array}{l}\text { B - } 10 \text { índices econômicos e } \\
\text { sociais nos } 13 \text { anos de governo } \\
\text { PT no Brasil } \\
\text { Link para matéria } \\
\text { Publicado em: } 02 \text { set. } 2016\end{array}$ & $\begin{array}{l}\text { E - Os números mais } \\
\text { sorteados na Mega-Sena e } \\
\text { outras estatísticas da loteria } \\
\text { Link para matériaPublicado } \\
\text { em: } 18 \text { set. } 2017\end{array}$ & $\begin{array}{l}\text { H - Que país é este? Um quiz } \\
\text { para além dos estereótipos } \\
\text { Link para matéria } \\
\text { Publicado em: } 18 \text { out. } 2016\end{array}$ \\
\hline $\begin{array}{l}\text { C - Censo de 1872: o retrato do } \\
\text { Brasil da escravidão } \\
\text { Link para matéria } \\
\text { Publicado em: } 27 \text { jun. } 2017\end{array}$ & $\begin{array}{l}\text { F - Em quais estados } \\
\text { brasileiros estes artistas são } \\
\text { mais populares } \\
\text { Link para matériaPublicado } \\
\text { em: } 18 \text { ago. } 2017\end{array}$ & $\begin{array}{l}\text { I - Você conhece os clássicos } \\
\text { da literatura brasileira? Faça } \\
\text { o teste } \\
\text { Link para matéria } \\
\text { Publicado em: } 18 \text { out. } 2017\end{array}$ \\
\hline
\end{tabular}

Fonte: elaborado pela autora.

No artigo Jornalismo de Dados: conceito e categorias, Mancini e Vasconcellos (2016) observam a forma como os dados quantificáveis aparecem nas narrativas jornalísticas de sites de todo o Brasil e propõem uma classificação do que seria o Jornalismo de Dados e o Jornalismo com Dados.

Há uma diferença, a nosso ver, entre reportagens $C O M$ e reportagens $D E$ dados. Enquanto o primeiro contemplaria reportagens que se apropriam de dados de forma ilustrativa, no segundo caso, os dados seriam a própria razão da reportagem. No primeiro caso, o dado quantitativo teria o papel de auxiliar ou de ilustrar uma reportagem; no segundo, o dado seria o próprio fundamento da pauta e a história das relações entre os dados conduziria, neste caso, a reportagem (VASCONCELLOS; MANCINI; BITTENCOURT, 2015, p. 15).

Os autores utilizam como base para sua classificação os estudos de Stray (2014), Silver (2014), Bradshaw (2014) e Hirst (2013) e propõem um quadro com um eixo vertical, que inicia a classificação do Jornalismo com Dados que segue para o Jornalismo de Dados, no outro extremo; e um eixo horizontal no qual são estabelecidas quatro Revista Pauta Geral-Estudos em Jornalismo, Ponta Grossa v.5, n.2, p. 240-254, Jul/Dez 2018. 


\section{ESTUDOS EM JORNALISMO}

10.5212/RevistaPautaGeral.v.5.i2.0014

categorias que visam avaliar as dimensões Investigativa, Interpretativa e Comunicativa das publicações (Quadro 2).

Quadro 2: Matriz que avalia os níveis do jornalismo de dados

\begin{tabular}{|c|c|c|c|c|c|}
\hline \multicolumn{2}{|c|}{$\begin{array}{c}\text { Categorias } \\
\text { X } \\
\text { Níveis de JD }\end{array}$} & $\begin{array}{c}\text { Busca e/ou } \\
\text { Elaboração própria } \\
\text { dos dados (criação } \\
\text { da base) }\end{array}$ & $\begin{array}{c}\text { Estrutura da base } \\
\text { (séries temporais, } \\
\text { categorias rankings, } \\
\text { tabelas) }\end{array}$ & $\begin{array}{l}\text { Visualização dos } \\
\text { dados (infografia) }\end{array}$ & $\begin{array}{l}\text { Interpretação dos } \\
\text { dados (texto) }\end{array}$ \\
\hline \multirow{5}{*}{ 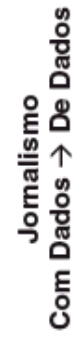 } & Nivel 1 & ㅁ & $\square$ & $\square$ & $\square$ \\
\hline & Nivel 2 & $\square$ & $\square$ & $\square$ & \\
\hline & Nível 3 & & & $\square$ & $\square$ \\
\hline & Nível 4 & & & $\square$ & \\
\hline & Nível 5 & & & & \\
\hline
\end{tabular}

Fonte: Mancini; Vasconcellos (2016, p. 77).

Na primeira dimensão, Investigativa - Extração/Organização, procura-se identificar se a reportagem utiliza dados que foram extraídos pelos próprios jornalistas de algum material bruto/base de dados, ou se produziram o próprio dado. $\mathrm{Na}$ segunda, Interpretativa - Argumentação, objetiva-se identificar se o texto jornalístico traz análises das relações entre os dados apresentados como forma de indicar causas e consequências do assunto enunciado. Na dimensão Comunicativa - Visualização Gráfica, busca-se avaliar se a reportagem traz algum tipo de gráfico e/ou infográfico de forma que o recurso utilizado promova ou incentive uma melhor compreensão do conteúdo (VASCONCELLOS; MANCINI; BITTENCOURT, 2015).

\section{Análise do corpus selecionado}

Utilizando as dimensões e as categorias citadas anteriormente, foi feita análise das reportagens indicadas no Quadro 1. Todas as nove matérias foram acessadas em fevereiro de 2018 e avaliadas qualitativamente conforme abaixo:

A - Os versos e traços da literatura de cordel: traz um histórico dos versos e desenhos que fazem parte dos populares folhetos. Não foi encontrado nesta reportagem algum elemento que utilizasse banco de dados ou recursos de visualização e interpretação, apenas conteúdo textual. Por não contemplar nenhuma das categorias, 
essa reportagem não se enquadra em nenhum nível da matriz de Mancini e Vasconcellos (2016).

B - 10 índices econômicos e sociais nos 13 anos de governo PT no Brasil: apresenta uma lista de tópicos que tratam de assuntos como salário mínimo, desemprego, pobreza, entre outros, cada um apresentando um gráfico e um texto relacionando motivos de causa e consequência. A reportagem atende então a dois critérios da matriz: visualização e interpretação, se enquadrando como Nível 3.

C - Censo de 1872: o retrato do Brasil da escravidão: esse especial utiliza os dados corrigidos do primeiro recenseamento feito no Brasil em 1872, dando destaque para a condição dos escravos. A reportagem gira em torno dos dados, traz gráficos elaborados com pesquisas feitas pelo próprio Nexo, infografias e interpretação dos dados, atendendo a todas as quatro categorias da matriz. Dessa forma, a reportagem se enquadra como Nível 1, Jornalismo de Dados.

D - A distribuição de pessoas com doutorado pelo Brasil: apresenta diversos gráficos que mostram o número de acadêmicos com a titulação de doutor registrados no currículo Lattes. Os dados que foram extraídos da plataforma do CNPq (Conselho Nacional de Desenvolvimento Científico e Tecnológico), em 2016, serviram de base para a criação de uma série gráficos que permitem uma melhor visualização da distribuição dessa classe. A notícia apenas apresenta os dados de forma ilustrativa sem se aprofundar ou desenvolver a interpretação. Podendo ser classificada como Nível 4, Jornalismo com Dados.

E - Os números mais sorteados na Mega-Sena e outras estatísticas da loteria: a notícia traz uma série de gráficos mostrando as ocorrências dos números sorteados pela Loteria Federal desde 1996. O Nexo utiliza os dados da LF para fazer os seus gráficos, porém deixa para o leitor a tarefa de interpretar as informações, podendo ser classificada como Nível 2.

F - Em quais estados brasileiros estes artistas são mais populares: nesse exemplo o Nexo retira informações do Youtube para montar seus gráficos e mostrar como a popularidade de artistas nacionais e internacionais vária em cada região. Assim como no caso "E", o Nexo se encarrega de extrair, estruturar e organizar os dados, deixando a comparação e interpretação para o leitor, portando, Nível 2.

G - O seu salário diante da realidade brasileira: trata-se de uma calculadora que compara o salário do leitor com o do restante dos habitantes da sua região e do Brasil. Revista Pauta Geral-Estudos em Jornalismo, Ponta Grossa v.5, n.2, p. 240-254, Jul/Dez 2018. 
Para elaborar a calculadora o Nexo utilizou os dados da Pnad (Pesquisa Nacional por Amostra de Domicílios). A primeira versão da calculadora foi publicada em 2016 e teve seus dados atualizados em janeiro de 2018. Tendo em vista o atendimento das mesmas categorias dos casos "E" e "F", classifica-se esse especial interativo como Nível 2.

H - Que país é este? Um quiz para além dos estereótipos: é um Interativo com dez questões sobre diversos países que muitas vezes são estereotipados por aspectos de miséria e baixo desenvolvimento econômico e social. Cada pergunta traz um dado pouco conhecido, e ao assinalar a resposta um pequeno texto com novos dados é mostrado. Esse exemplo pode ser enquadrado no Nível 5, pois nessa categoria são enquadradas "[...] as publicações curtas, que citam dados, mas não exploram os dados contextualmente ou visualmente" (VASCONCELLOS; MANCINI; BITTENCOURT, 2015, p. 21).

I - Você conhece os clássicos da literatura brasileira? Faça o teste: nesse quiz são apresentadas dez obras de autores diferentes para que o leitor identifique quem escreveu a obra entre as alternativas disponíveis. Não existe a utilização de dados, apenas textos de referência às obras da literatura. Portanto, esse interativo não pôde ser classificado em nos níveis da matriz.

Feitas análises, constatou-se uma maior concentração de matérias $(E, F, G)$ classificadas como Nível 2 - Jornalismo de Dados; e o restante se dividiu entre os demais níveis, uma em cada. Duas matérias não eram baseadas em dados $(A, I)$, portanto não puderam ser analisadas dentro do escopo da pesquisa. Para uma melhor visualização do resultado foi elaborado o Quadro 3.

Quadro 3: Quadro de resultados

\begin{tabular}{|c|c|l|c|}
\hline Nível & Identificação & \multicolumn{1}{|c|}{ Título } & Editoria \\
\hline Nível 1 & C & $\begin{array}{l}\text { Censo de 1872: o retrato do Brasil da } \\
\text { escravidão }\end{array}$ & Especial \\
\hline Nível 2 & E, F, G & $\begin{array}{l}\text { Os números mais sorteados na Mega-Sena e } \\
\text { outras estatísticas da loteria } \\
\text { Em quais estados brasileiros estes artistas são } \\
\text { mais populares } \\
\text { O seu salário diante da realidade brasileira }\end{array}$ & Gráfico \\
Nível 3 & B & $\begin{array}{l}\text { 10 índices econômicos e sociais nos 13 anos } \\
\text { de governo PT no Brasil }\end{array}$ & Especial \\
\hline
\end{tabular}

Revista Pauta Geral-Estudos em Jornalismo, Ponta Grossa v.5, n.2, p. 240-254, Jul/Dez 2018. 
ESTUDOS EM JORNALISMO

10.5212/RevistaPautaGeral.v.5.i2.0014

\begin{tabular}{|c|c|l|c|}
\hline Nível 4 & D & $\begin{array}{l}\text { A distribuição de pessoas com doutorado pelo } \\
\text { Brasil }\end{array}$ & Gráfico \\
\hline Nível 5 & $\mathrm{H}$ & $\begin{array}{l}\text { Que país é este? Um quiz para além dos } \\
\text { estereótipos }\end{array}$ & Interativo \\
\hline Não se aplica & A, I & $\begin{array}{l}\text { Os versos e traços da literatura de cordel } \\
\text { Você conhece os clássicos da literatura } \\
\text { brasileira? Faça o teste }\end{array}$ & Especial \\
\hline
\end{tabular}

Fonte: elaborado pela autora.

\section{Considerações finais}

Neste artigo, observou-se a evolução e expansão do Jornalismo de Dados ao longo dos anos, que se potencializou nos anos $2000 \mathrm{com}$ o advento da tecnologia e das políticas de open data. Fato que se confirma nos exemplos de sucesso trazidos no livro produzido pelo Knight Center, Jornalismo Inovador na América Latina. Entre eles, o do jornal digital Nexo, nosso objeto de análise.

Durante a pesquisa bibliográfica, reconheceu-se que podem existir diferenças nas formas de produção de notícias utilizando o JGD. A fim de estabelecer uma análise empírica do tipo de conteúdo elaborado pelo Nexo. Utilizou-se das categorias apresentadas por Vasconcellos; Mancini e Bittencourt (2015) como forma de verificar se o jornalismo praticado se enquadraria como Jornalismo de Dados ou Jornalismo com Dados.

Ao final das análises, averiguou-se que a matriz apresentada no Quadro 2 cumpre de forma eficaz o objetivo de classificar os tipos de JGD, tendo em vista que todos os exemplos selecionados para este estudo de caso, que continham dados, puderam ser qualificados de acordo com as descrições de Vasconcellos; Mancini e Bittencourt (2015).

Observa-se ainda que duas das três notícias da editoria Gráfico analisadas puderam ser enquadradas como Nível 2, Jornalismo de Dados. O que pode indicar, de fato, uma tendência desta seção em publicar conteúdos que utilizem a extração, estruturação e visualização dos dados, deixando apenas a interpretação a cargo do leitor.

Nos níveis 1, 3, 4 e 5 têm-se um exemplo para cada. Destaca-se que a reportagem especial baseada no primeiro recenseamento realizado em 1872, no Brasil, traz um grande de trabalho de pesquisa desenvolvida pelo Nexo e atendendo a todas as categorias da matriz. E para o Nível 5, o quiz Que país é esse? utiliza dados de relatórios muito densos de maneira límpida, como uma matéria de "curiosidades" para o leitor, sem Revista Pauta Geral-Estudos em Jornalismo, Ponta Grossa v.5, n.2, p. 240-254,

Jul/Dez 2018. 
utilizar gráficos ou infográficos, classificando-se como um exemplo de Jornalismo com Dados.

Por fim, considera-se que a utilização do JGD pode, de fato, ser uma forma de atrair os leitores e dar mais credibilidade à publicação. Pois, quando as análises foram feitas, em fevereiro de 2018, o ranking das matérias mais lidas trazia publicações feitas entre maio e outubro de 2017. O que indica que as matérias baseadas em dados podem ter uma validade maior e um interesse prolongado, pois existiam outros conteúdos mais recentes nas editorias analisadas que não tiveram o mesmo destaque entre os hits (seção de matérias acessadas). Observa-se ainda, a atenção do Nexo em manter atualizados os dados da calculadora do Interativo $O$ seu salário diante da realidade brasileira, o que confere uma validade ainda maior para a publicação e contribui para que ela seja mantida entre o ranking das mais lidas.

Pela avaliação feita, o Nexo tenta manter o seu objetivo de ser uma publicação que contribua para o debate público, valorizando o jornalismo de contexto, que muitas vezes pode ser favorecido pela utilização do JGD. O que corrobora com os estudos vistos no desenvolvimento teórico que afirmam que a utilização dos dados pode ser um caminho para enfrentar a crise no modelo de negócio do jornalismo.

\section{Referências}

ANDERSON, C. W.; BELL, Emily; SHIRKY, Clay. Jornalismo Pós-Industrial: adaptação aos novos tempos. Revista de Jornalismo ESPM, abril-junho de 2013, p. 30-89.

BRADSHAW, Paul. O que é Jornalismo de Dados, in Manual de Jornalismo de Dados, 2014. In: GRAY, Jonathan; BOUNEGRU, Liliana; CHAMBERS, Lucy. Manual de jornalismo de dados. Open Knowledge Foudation, 2014.

CARNETI, Karen. Pesquisadores querem testar 'visão' de inteligência artificial com imagens. 2015. Disponível em: <https://exame.abril.com.br/tecnologia/pesquisadorestrabalham-em-teste-de-turing-para-visao-de-inteligencias-artificiais/>. Acesso em: 25 mai. 2018.

CASTELLS, Manuel. A galáxia da internet. Rio de Janeiro: Jorge Zahar, 2003.

GRAY, Jonathan; BOUNEGRU, Liliana; CHAMBERS, Lucy. Manual de jornalismo de dados. Open Knowledge Foudation, 2014.

HIRST, Tony. Several takes on defining Data Journalism. 2013. Disponível em:<http://schoolofdata.org/2013/06/11/several-takes-on-defining-data-journalism/>. Acesso em: 25 jan. 2018. 
HOLOVATY, Adrian. A fundamental way newspaper sites need to change. 2006. Disponível em: <http://www.holovaty.com/writing/fundamental-change/>. Acesso em: 25 mai. 2018.

LEVY, Pierre. As tecnologias da inteligência. São Paulo: Editora 34, 1996.

LEVY, Steven. Can an algorithm write a better news story than a human reporter?. 2012. Disponível em:< https://www.wired.com/2012/04/can-an-algorithm-write-a-betternews-story-than-a-human-reporter/>Acesso em: 03 mai. 2018.

MANCINI, Leonardo; VASCONCELLOS, Fabio. Jornalismo de Dados: conceito e categorias. Revista Fronteiras: estudos midiáticos, São Leopoldo, v. 18, n. 1, p.69-82, abr. 2016. Quadrimenstral. Disponível em: <http://revistas.unisinos.br/index.php/fronteiras/article/viewFile/fem.2016.181.07/5300>. Acesso em: 25 mai. 2018.

MEYER, Philip. Precision jornalism: a reporter's introduction to social science methods. Rowman \& Littlefield Publishers, 2002.

MIELNICZUK, Luciana. Características e implicações do jornalismo na web. 2001.Disponível <http://www.facom.ufba.br/jol/pdf/2001_mielniczuk_caracteristicasimplicacoes.pdf>. Acesso em: 25 mai. 2018.

MIOLI, Teresa; NAFRÍA, Ismael. Jornalismo Innovador na América Latina. Texas: Centro Knight para o Jornalismo nas Américas, 2017. Disponível em: <https://knightcenter.utexas.edu/books/PIPortugues.pdf>. Acesso em: 25 jan. 2018.

NEXO. Sobre o Nexo. 2015. Disponível em: <https://www.nexojornal.com.br/about/Sobreo-Nexo>. Acesso em: 25 mai. 2018.

PIMENTEL, Matheus. Qual o significado do prêmio recebido pelo 'Nexo' para o jornalismo no Brasil. Nexo. Disponível em: <https://www.nexojornal.com.br/expresso/2017/10/09/Qual-o-significado-dopr\%C3\%AAmio-recebido-pelo-Nexo-para-o-jornalismo-no-Brasil>. Acesso em: 25 mai. 2018.

RODRIGUES, Kelly De Conti. Jornalismo de Dados: influência da construção narrativa no agendamento midiático. In: Ciências da Comunicação: Circularidades Teóricas e Práticas acadêmicas. (Org.s) BULHÕES, Marcelo; MORAIS, Osvando J. Sarapuí: OJM Casa Editorial, 2015.

ROSEGRANT, Susan. Revealing the roots of a riot. ISR Sampler, Ann Arbor, $1^{\circ} \mathrm{abr}$. 2011. Disponível em: <http://home.isr.umich.edu/sampler/revealing-the-roots-of-a-riot/>. Acesso: 25 mai. 2018.

SILVER, Nate. What the Fox Knows. 2014. Disponivel em:<http://fivethirtyeight.com/features/what-the-fox-knows/>. Acesso em: 25 mai. 2018. 
STRAY, Jonathan. The Data Journalist's Eyes, An Introduction. Disponível em:<http://towcenter.org/blog/the-data-journalists-eye-an-introduction/>. Acesso em: 25 mai. 2018.

TRÄSEL, Marcelo Ruschel. Entrevistando Planilhas: Estudo das Crenças e do Ethos de um Grupo de Profissionais de Jornalismo Guiado por Dados no Brasil. 2014. 314 f. Tese (Doutorado) - Curso de Comunicação Social, Pontifícia Universidade Católica do Rio Grande do Sul, Porto Alegre, $2014 . \quad$ Disponível em:<http://tede.pucrs.br/tde_arquivos/7/TDE-2014-10-02T061010Z-

5315/Publico/461784.pdf>. Acesso em: 25 mai. 2018.

TRÄSEL, Marcelo. Jornalismo guiado por dados: aproximações entre a identidade jornalística e a cultura hacker. Estudos em Jornalismo e Mídia, [s.I.], v. 11, n. 1, p.291304, 4 maio 2014. Universidade Federal de Santa Catarina (UFSC). http://dx.doi.org/10.5007/1984-6924.2014v11n1p291.

em:<https://periodicos.ufsc.br/index.php/jornalismo/article/view/1984-

Disponível 6924.2014v11n1p291/27193>. Acesso em: 25 mai. 2018.

VASCONCELLOS, Fábio; MANCINI, Leonardo; BITTENCOURT, Carolina. Cinco categorias de Jornalismo de Dados ou uma proposta para problematizar o Jornalismo a partir de dados no Brasil. In: SEMINÁRIO DE PESQUISA EM JORNALISMO INVESTIGATIVO, 2015, São Paulo. Anais... São Paulo: Abraji, 2015. p. 1 - 24. Disponível em:

<http://www.abraji.org.br/seminario/PDF/2/carolina_bittencourt_fabio_vasconcellos_leonar do_mancini.pdf>. Acesso em: 25 mai. 2018.

\section{Enviado em 11/06/2018.}

Publicado em 21/12/ 2018. 